\title{
Analysis of the Reaction Force of a Bunch of Rice Stalks Undergoing Forced Displacement
}

\section{Hirai, Yasumaru}

Laboratory of Bioproduction and Environment Information Sciences, Division of Bioproduction and Environment Information Sciences, Department of Bioproduction Environmental Sciences, Graduate school of Bioresoruce adn Bioenvironmental Sciences Kyushu University

\section{Inoue, $\mathrm{Eiji}$}

Laboratory of Bioproduction and Environment Information Sciences, Division of Bioproduction and Environment Information Sciences, Department of Bioproduction Environmental Sciences, Faculty of Agliculture, Kyushu Univesity

Fukushima, Takashi

Laboratory of Bioproduction and Environment Information Sciences, Division of Bioproduction and Environment Information Sciences, Department of Bioproduction Environmental Sciences, Graduate school of Bioresoruce adn Bioenvironmental Sciences Kyushu University

\section{Ueka, Ikuo}

Laboratory of Bioproduction and Environment Information Sciences, Division of Bioproduction and Environment Information Sciences, Department of Bioproduction Environmental Sciences, Graduate school of Bioresoruce adn Bioenvironmental Sciences Kyushu University

他

https://doi.org/10.5109/4541

出版情報：九州大学大学院農学研究院紀要. 48 (1/2)，pp. 175-186，2003-10-01. Faculty of Agriculture, Kyushu University

バージョン :

権利関係 : 


\title{
Analysis of the Reaction Force of a Bunch of Rice Stalks Undergoing Forced Displacement
}

\author{
Yasumaru HIRAI*, Eiji INOUE ${ }^{\dagger}$, Takashi FUKUSHIMA*, \\ Ikuo UEKA* and Ken MORI
}

\author{
Laboratory of Bioproduction and Environment Information Sciences, Division of Bioproduction and \\ Environment Information Sciences, Department of Bioproduction Environmental Sciences, \\ Faculty of Agriculture, Kyushu University, Fukuoka 812-8581, Japan \\ (Received June 17, 2003 and accepted July 15, 2003)
}

\begin{abstract}
The analytical method for the reaction force of crop stalks undergoing forced displacement, which has been verified for a bunch of wheat stalks, was applied to analysis of a bunch of rice stalks. The reaction forces of the rice stalk's bunches with various initial shapes were analyzed, and the accuracy was assessed by experimental results. The analytical results involved a certain amount of error, depending on the accuracy of the simulated initial shape, but were reasonably close. It was demonstrated that the reaction force according to the initial shape could be predicted utilizing the previous analytical method in the case of the bunch of rice stalks as well.
\end{abstract}

\section{INTRODUCTION}

In the field of agricultural machines, it would be advantageous to assess a performance of the machine taking the crop properties into account at the design stage instead of through actual machine tests, especially from the viewpoints of cost reduction, shortening of the development period, and clarification of optimum machine operations according to crop conditions. In order to improve the process of design and development, investigations of physico-mechanical properties and behavior of crops caused by machine operations are important.

A variety of physico-mechanical properties of biological materials have been investigated for the purpose of applying them to machine design, mechanical processes and lodging problems (Moustafa et al., 1968; Muller, 1988; O'Dogherty et al., 1995; Szot and Skubisz, 1984). On the other hand, instances of their application to machine design are very few, and machine performance is still assessed by field tests. One reason for the low number of real applications is the existence of very few studies focusing on the mechanical response of the crop stalk during actual machine operations. Thus, the authors have investigated deflection response (characteristics) related to gathering operations of a combine harvester reel based on a mechanical model of a crop stalk. A mechanical model of a crop stalk with a heterogeneous cross-section was proposed, based on bending theory regarding an elastic beam (Timoshenko, 1958), and also a calculation method of

\footnotetext{
* Laboratory of Bioproduction and Environment Information Sciences, Division of Bioproduction and Environment Information Sciences, Department of Bioproduction Environmental Sciences, Graduate school of Bioresource and Bioenvironmental Sciences Kyushu University

+ Corresponding author (E-mail: inoeiji@brs.kyushu-u.ac.jp)
} 
flexural rigidity for materials with a heterogeneous cross-section was verified by deflection tests using piano wire (Hirai et al, 2000). An extended model that takes into account the effect of a crop ear was proposed, and the relationships between the deflection and deflection force (horizontal force component) acting on a bunch of crop stalks were analyzed under a standing crop condition (Hirai et al., 2002a). The effects of frictional force and the vertical force component were considered, and horizontal and vertical reaction forces on a bunch of crop stalks were analyzed (Hirai et al., 2002b).

Currently, the analytical method for the reaction force, taking into account the initial shape of crop stalks, has been developed, and the validity of the application has been shown under conditions of a single wheat stalk (Hirai et al., 2003a), a bunch of wheat stalks (Hirai et al., 2003b) and a single rice stalk (Hirai et al., 2003c). In the present study, the analytical method is applied to a bunch of rice stalks. Reaction forces are measured under various initial shapes of the rice stalks and are compared with the analytical ones. The analytical results involve a certain amount of error, depending on the initial shape of the rice stalk's bunch, but are reasonably close. It is demonstrated that the reaction force according to the initial shape can be predicted utilizing the previous analytical method in the case of the bunch of rice stalks as well.

\section{EXPERIMENTAL SYSTEM AND METHOD}

\section{Experimental system}

Reaction forces of a bunch of rice stalks undergoing forced displacement were measured using the experimental system as shown in Fig. 1. This system is composed of an L-shaped sensor, oil-hydraulic apparatus, low pass filter (KYOWA, LF-303A), strain amplifier (KYOWA, DPM-612B), data-recorder (TEAC, DR-C1MK2), notebook computer (TOSHIBA, SA65C/4), digital video camera (SONY, DCR-VX1000), criterion makers and subject test material (21 pieces of rice stalks). The specifications of the $\mathrm{L}$-shaped sensor are shown in the previous paper (Hirai et al., 2002a). The L-shaped sensor is capable of detecting two mutual perpendicular force components by using bridge circuits composed of strain gauges, which are mounted on the body of sensor. The L-shaped sensor is attached to the rod of the oil-hydraulic cylinder. The horizontal movement and speed of the sensor can be controlled by oil-hydraulic pump. The height of the material being tested is adjustable using stand to vary the acting height of the sensor. The height of the sensor is arranged in $70 \sim 80 \%$ of the appearance height of the rice stalks. The material is deflected by the horizontal motion of the sensor, while at that moment horizontal and vertical reaction forces are measured simultaneously. High frequency signals, caused by a slight vibration during horizontal movement, are removed from original electrical signals of the sensor by a low pass filter. The signals are then amplified and recorded on a data recorder, which converts analog data into digital data automatically. The deflection shape of the rice stalks during the experiment is recorded by means of a digital video camera. The data of coordinates of the shape are obtained by processing image data utilising commercial software (Library, MOVE-TR32/2D).

\section{Experimental method}

Measurements were made on 'Mineasahi' variety of rice stalks. The roots and leaves 


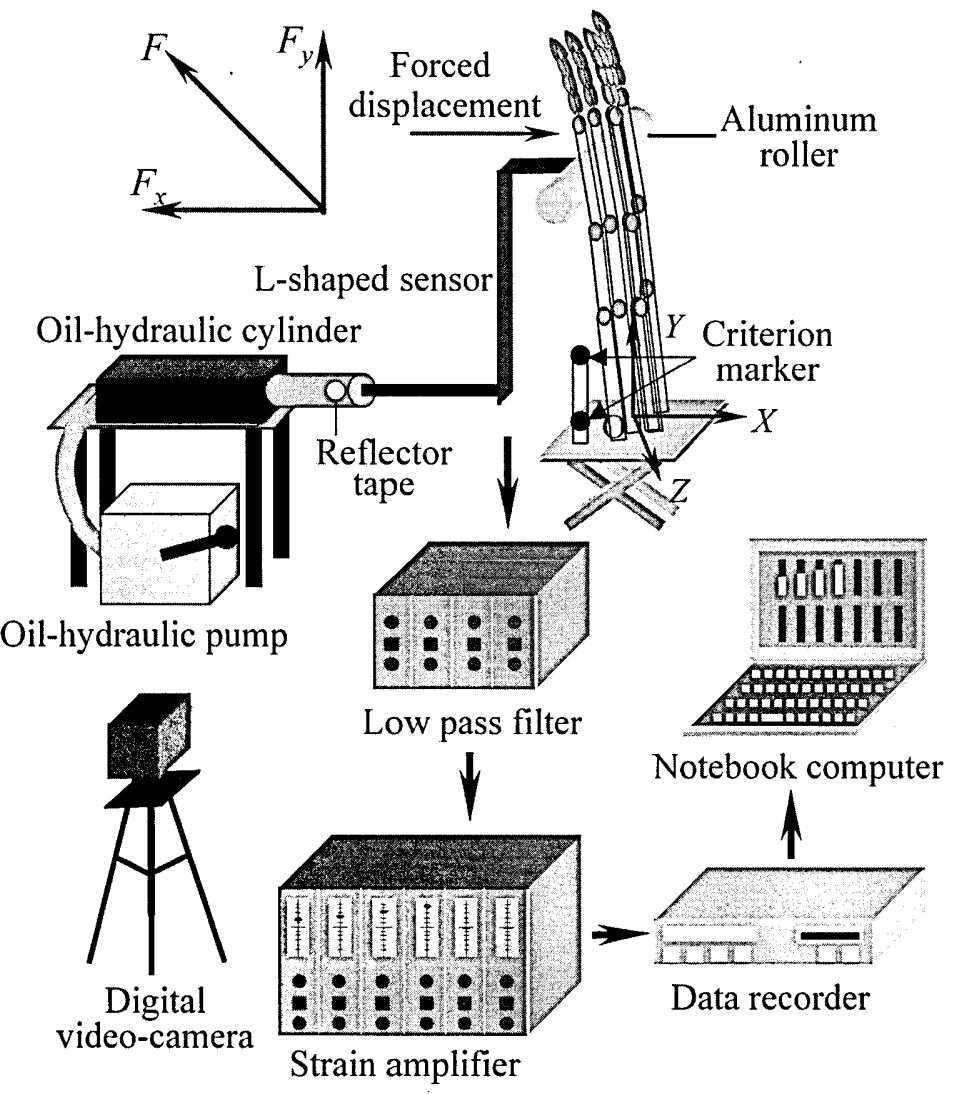

Fig. 1. Composition of experimental system

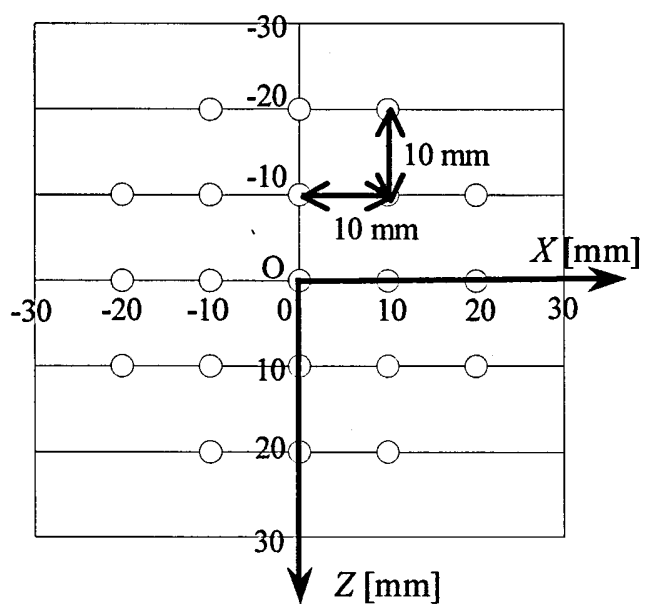

Fig. 2. Basal arrangement of a bunch of rice stalks 
were removed and 21 pieces of rice stalks (a bunch of rice stalks) were fixed to a piece of wood using a quick-drying glue at the base. The arrangement of the rice stalks is shown Fig. 2. The rice stalk's samples used in this experiment were consisted of 6 bunches taken in 2001 from 18 to 23 October. Each was used twice, to avoid adverse effects on results from the use of fatigued or damaged stalks. One data set was used for assessing the accuracy of this experiment. This experiment was conducted under a quasi-static condition; the speed of the sensor was about $10 \mathrm{~mm} / \mathrm{s}$. Following this experiment, a deflection test (Hirai et al., 2000) for calculating the flexural rigidity of each rice stalk composing the bunch was carried out. Data regarding flexural rigidity, length, weight and moisture content are shown in Table 1.

Table 1. Data regarding rice stalk flexural rigidity, length, weight and moisture content

\begin{tabular}{lcccc}
\hline $\begin{array}{c}\text { Material and } \\
\text { location }\end{array}$ & $\begin{array}{c}\text { Flexural } \\
\text { rigidity } \\
\left(\mathrm{kN} \mathrm{mm}^{2}\right)\end{array}$ & $\begin{array}{c}\text { Length } \\
(\mathrm{mm})\end{array}$ & Weight (N) & $\begin{array}{c}\text { Moisture } \\
\text { content } \\
(\%)\end{array}$ \\
\hline Rice stalk No. 1 & & & & \\
Internode 1 & $41.2(12.9)$ & $175(48)$ & - & - \\
Internode 2 & $43.3(21.9)$ & $232(65)$ & - & - \\
Internode 3 & $12.1(3.4)$ & $368(40)$ & - & - \\
Whole stalk & $30.1(9.2)$ & $775(50)$ & 0.044 & 61.0 \\
Ear & - & 187 & 0.039 & 24.3 \\
\hline Rice stalk No. 2 & & & & - \\
Internode 1 & $28.0(10.1)$ & $231(55)$ & - & - \\
Internode 2 & $26.4(15.0)$ & $203(27)$ & - & - \\
Internode 3 & $8.1(2.1)$ & $333(23)$ & - & 24.7 \\
Whole stalk & $19.8(5.5)$ & $767(43)$ & 0.04 & \\
Ear & - & 184 & 0.028 & \\
\hline
\end{tabular}

* Figures in parentheses represent standard deviation

\section{SIMULATION OF THE INITIAL SHAPE OF A BUNCH OF RICE STALKS}

\section{Assessment parameter of the initial shape and the equation of curvature describing the initial bending}

Two instances of actual images of the initial shape are shown in Figures 3 (a) and 4 (a), and their initial shapes plotted are shown in Figures 3 (b) and 4 (b). Commercial software (Library, MOVE-TR32/2D) was used for processing the images. Also, because it was difficult to distinguish each individual rice stalks composing a bunch from image data, the features of the initial shape were formed by plotting the outline of the bunch. In the present study, a type of the initial shape shown in Fig. 3 (No. 1) was defined as "negative shape" and the shape shown in Fig. 4 (No. 2) was defined as "positive shape".

The initial shape of a bunch of rice stalk was calculated by the same procedure as the case of wheat stalk's bunch previously proposed (Hirai et al. 2003b). First, using four sets of coordinate data $\left(x_{B L}, 0\right),\left(x_{B R}, 0\right),\left(x_{T L}, y_{T L}\right),\left(x_{T R}, y_{T R}\right)$, left and right lodging angles 


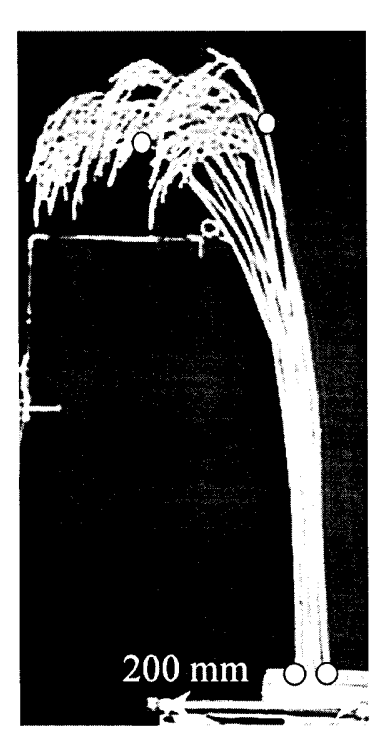

(a)

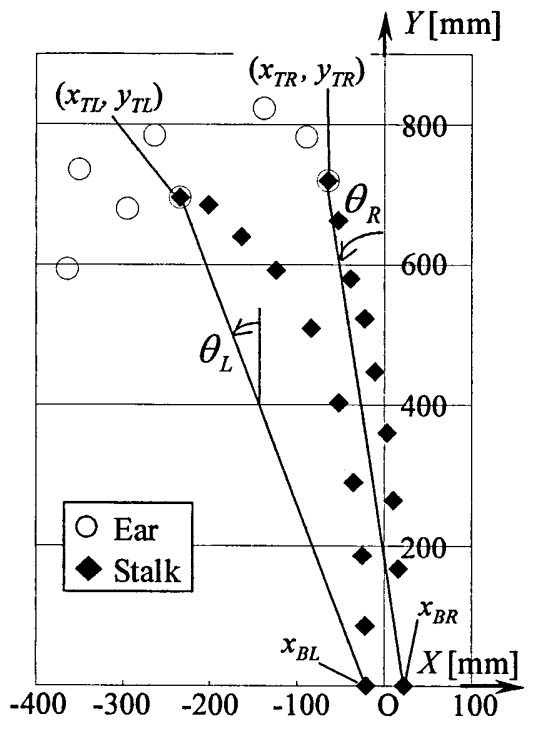

(b)

Fig. 3. Initial shape of a bunch of rice stalk (No. 1)

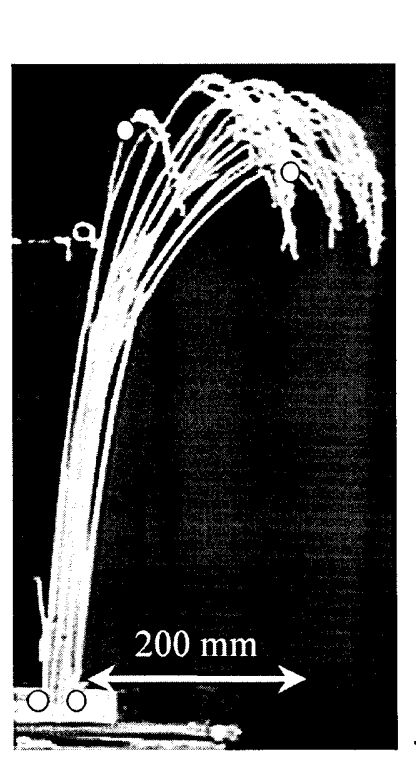

(a)

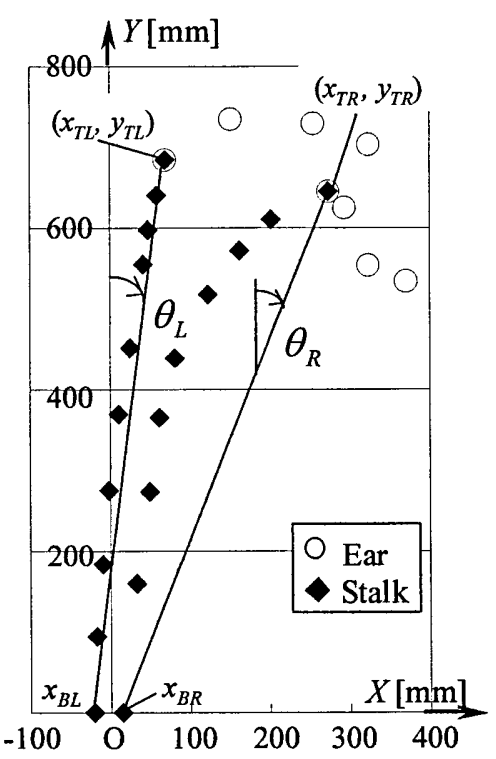

(b)

Fig. 4. Initial shape of a bunch of rice stalk (No. 2) 
were calculated by the following equation (1). These two lodging angles were defined as assessment parameters of the initial shape.

$$
\theta_{L}=\tan ^{-1}\left(\frac{x_{T L}-x_{B L}}{y_{T L}}\right), \theta_{R}=\tan ^{-1}\left(\frac{x_{T R}-x_{B R}}{y_{T R}}\right)
$$

where, $x_{B L}$ is the $x$ coordinate at the left side base in mm; $x_{B R}$ is the $x$ coordinate at the right side base in mm; $x_{T L}, y_{T L}$ are the $x, y$ coordinates at the left side tip in mm; $x_{T R}, y_{T L}$ are the $x, y$ coordinates at the right side tip in $\mathrm{mm} ; \theta_{L}$ is the left lodging angle in rad; and $\theta_{R}$ is right lodging angle in rad. The lodging angles $\theta_{L}, \theta_{R}$ were then taken to be positive in the clockwise direction from the $Y$ axis. Next, lodging angles of individual rice stalks composing a bunch was calculated based on the assessment parameters of the initial shape. The variation rate $\beta$ of the lodging angle on $X$ direction was determined by the following equation (2).

$$
\beta=\frac{\theta_{R}-\theta_{L}}{x_{B R}-x_{B L}}
$$

where, $\beta$ is the variation rate of the lodging angle in $\mathrm{rad} / \mathrm{mm}$.

The basal coordinates of a bunch of rice stalks, which was arranged experimentally, were assumed to be known information, and then the lodging angle $\theta_{i}$ of an arbitrary rice stalk (subscript $i$ indicates the rice stalk's number) was calculated by the following equation (3).

$$
\theta_{i}=\theta_{L}+\beta\left(x_{i}-x_{B L}\right)
$$

where, $x_{i}$ is the basal $x$ coordinate of the $i^{\text {th }}$ rice stalk in $\mathrm{mm} ; \theta_{i}$ is the lodging angle of the $i^{\text {th }}$ rice stalk in rad.

Finally, based on the lodging angle calculated by Eq.(3), the initial shape of individual rice stalks composing the bunch was simulated utilizing the equation of curvature describing the initial bending as follows.

$$
\frac{d \theta}{d s}=\frac{W\left(E_{0}-x_{d}\right)}{D_{j}}+\frac{F_{S}^{\prime \prime}}{\left(1+F_{S}^{\prime 2}\right)^{3 / 2}}
$$

where, $F_{s}=A\left(\frac{y_{s}}{L_{a p}}\right)^{n}, F_{S}{ }^{\prime}=\frac{d F_{S}}{d y_{s}}, F_{s}{ }^{\prime \prime}=\frac{d^{2} F_{s}}{d y_{s}}, E_{0}=x_{0}+\left(E_{l} \sin \theta_{0}\right) / 2$

and: $A$ is the amplitude of intrinsic shape in $\mathrm{mm} ; D_{j}$ is the flexural rigidity of the $j^{\text {th }}$ internode in $\mathrm{N} \cdot \mathrm{mm}^{2} ; E_{l}$ is the length of an ear in $\mathrm{mm} ; E_{0}$ is the $x$ coordinate of center of an ear in the initial position in $\mathrm{mm} ; F_{S}$ is the intrinsic shape function of a rice stalk; $F_{S}{ }^{\prime}$ and $F_{S}{ }^{\prime \prime}$ are the first and second derivation of the intrinsic shape function $F_{s} ; L_{a p}$ is the appearance height of intrinsic shape in $\mathrm{mm} ; n$ is the exponent of integer equals or more than $3 ; s$ is the length of arc along the stalk in mm; $W$ is the weight of an ear in $\mathrm{N} ; x_{0}$ and $x_{d}$ are the $x$ coordinates at the tip in the initial position and of the reference stalk in mm; $y_{s}$ is the height of the intrinsic shape in mm; $\theta$ is the deflection angle of the reference stalk in rad; $\theta_{0}$ is the deflection angle at the tip in the initial position in rad. Here, $x_{d}, y_{s}$ and $F_{s}$ are function of $s$. The Eq.(4) is a differential equation regarding the deflection angle. To calculate the deflection angle, the Runge-Kutta Method was applied. Also, the deflection 
and height ( $x, y$ coordinates) of the initial shape were calculated by integrating increments in $x, y$ directions calculated from deflection angle. For the value of exponent $n$ in the intrinsic shape function, the integer from 3 to 6 was determined in the case of a single rice stalk, based on the $x, y$ coordinates at the tip of the rice stalk (Hirai et al. 2003b). On the other hand, the lodging angle used in this analysis doesn't involve the information to assess each value of exponent. Thus, the exponent value 3, which was most frequent in the case of single rice stalk, was used for the analysis of a bunch of rice stalks. Details of the simulation are shown in previous paper (Hirai et al., 2003a; Hirai et al. 2003b).

\section{Simulated results of the initial shape of rice stalk's bunch}

The assessment parameters of No. 1 (negative shape) shown in Fig. 3 were -17.0 degrees (left lodging angle) and -6.9 degrees (right lodging angle); on the other hand, those of No. 2 (positive shape) shown in Fig. 4 were 7.5 degrees and 21.8 degrees, respectively. The simulated results of the initial shape of rice stalks are shown in Figures 5 and 6 . The simulated results were projected on the $x-y$ plane for the sake of comparing them with actual images. In the present study, the simulated results were compared with actual images in terms of just the outline of the bunch. The distribution of individual stalks composing the bunch involved a certain amount of error, and further the ear's shape had some error due to assumption of its rigid body. However, it was judged that the features of the bunch of rice stalks were simulated sufficiently. From comparison results, it was shown that the effect of the initial shape of the bunch could be considered for analysis of reaction forces.

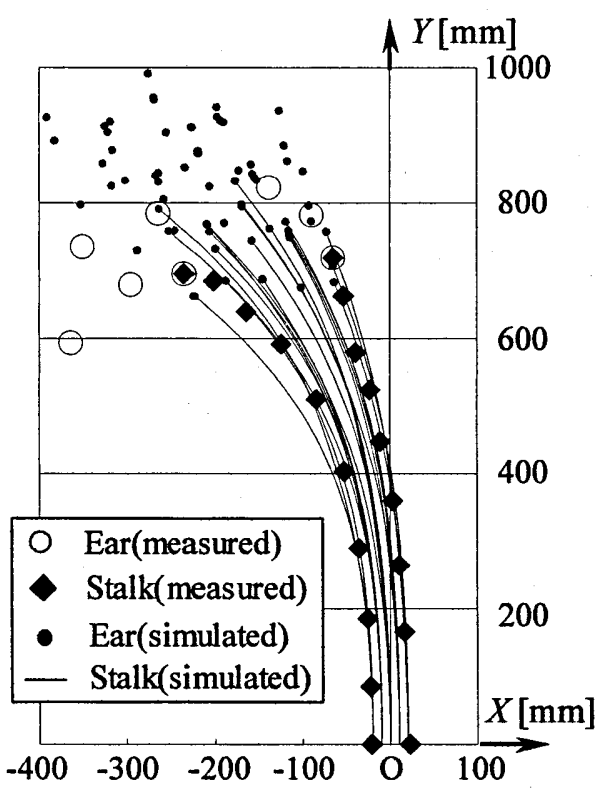

Fig. 5. Simulated result of the initial shape of rice stalks (No. 1) 


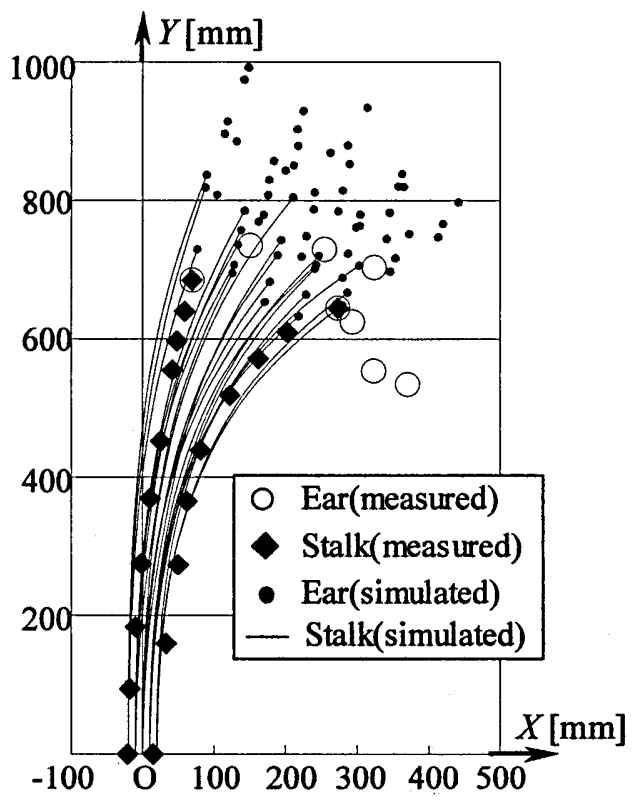

Fig. 6. Simulated result of the initial shape of rice stalks (No. 2)

\section{ANALYSIS OF REACTION FORCES OF A BUNCH OF RICE STALKS}

The equation of curvature describing bending of a rice stalk undergoing forced displacement

The resultant force acting on a rice stalk undergoing forced displacement is composed of normal force $P_{n}$ and tangential force $P_{t}$ (Fig. 7). The tangential force $P_{t}$ gives the elongation on the surface of stalk at its loading point, but the effect on the bending was considered to be very slight. Thus, only the bending moment due to the normal force and concentrated load were considered. The bending moment $M$ acting on the stalk is obtained as follows.

(I) $0 \leq y_{d} \leq y_{p}$ $M=P_{n} \cos \theta_{p}\left(y_{p}-y_{d}\right)+P_{n} \sin \theta_{p}\left(x_{p}-x_{d}\right)+W\left(E-x_{d}\right)$

(II) $y_{p} \leq y_{d} \leq y_{t}$ $M=W\left(E-x_{d}\right)$

where, $E=x_{t}+\left(E_{l} \sin \theta_{t}\right) / 2$

and: $E$ is the the $x$ coordinate of the center of the ear in mm; $M$ is the bending moment acting on a rice stalk in $\mathrm{N} \cdot \mathrm{mm} ; P_{n}$ is the normal force acting on a rice stalk in $\mathrm{N} ; y_{d}$ is the $y$ coordinates of the reference stalk, $\mathrm{mm} ; x_{p}, y_{p}$ are the $x, y$ coordinates at loading point in 


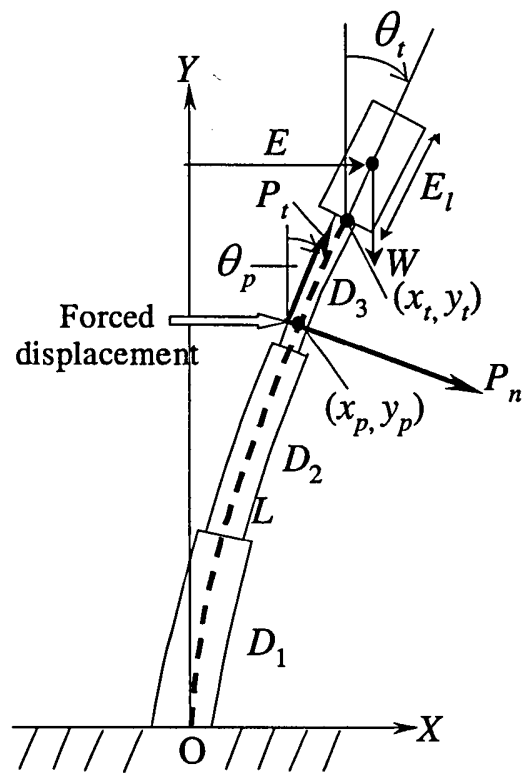

Fig. 7. Mechanical model of a rice stalk undergoing forced displacement

$\mathrm{mm} ; x_{t}, y_{t}$ are the $x, y$ coordinates at the tip of a rice stalk in mm; $\theta_{p}$ is the deflection angle at loading point in rad; $\theta_{t}$ is the deflection angle at the tip of a rice stalk in rad.

Further, when the effect of intrinsic shape $F_{S}$ is considered, the equation of curvature describing bending of a rice stalk is derived as follows:

$$
\frac{d \theta}{d s}=\frac{M}{D_{j}}+\frac{F s^{\prime \prime}}{\left(1+F s^{\prime}\right)^{3 / 2}}
$$

Also, the reaction force of a rice stalk is composed of normal reaction force $P_{r}$, balanced by normal force $P_{n}$, and frictional force $f$, which is the resistance force against tangential force $P_{t}$. Thus, reaction forces $F_{x}, F_{y}$ in horizontal and vertical directions are obtained as follows:

$$
\left\{\begin{array}{l}
F_{x}=P_{r} \cos \theta_{p}-f \sin \theta_{p} \\
F_{y}=P_{r} \sin \theta_{p}+f \cos \theta_{p}
\end{array}\right.
$$

Utilizing Equations (5), (6) and (7), the reaction force of a bunch of rice stalks was analyzed. Now, the coefficient of friction 0.14 , which was determined from experimental results of a single wheat stalk, was used in this analysis. Details of the simulation are shown in previous paper (Hirai et al. 2003b).

\section{Comparison between calculated and experimental values of the reaction force}

Comparisons of reaction forces between numerical analysis and measurement are 
shown in Figures 8 (No. 1) and 9 (No. 2). The simulated results in both case of initial shape agreed fairy well with measured values. Also, because kinetic friction is assumed constant in this analysis, discontinuous change of the vertical reaction force was shown around the origin involving a change of frictional direction. The disagreement with the real data at the beginning of the simulation was caused by error in determining the contact point between the sensor and a rice stalk due to error of the simulated initial shape. Difference of force increment in the horizontal force was due to difference of distribution of the initial shape between analysis and measurement. Thus, the analytical results regarding the horizontal and vertical reaction forces expressed a slight degree of error in

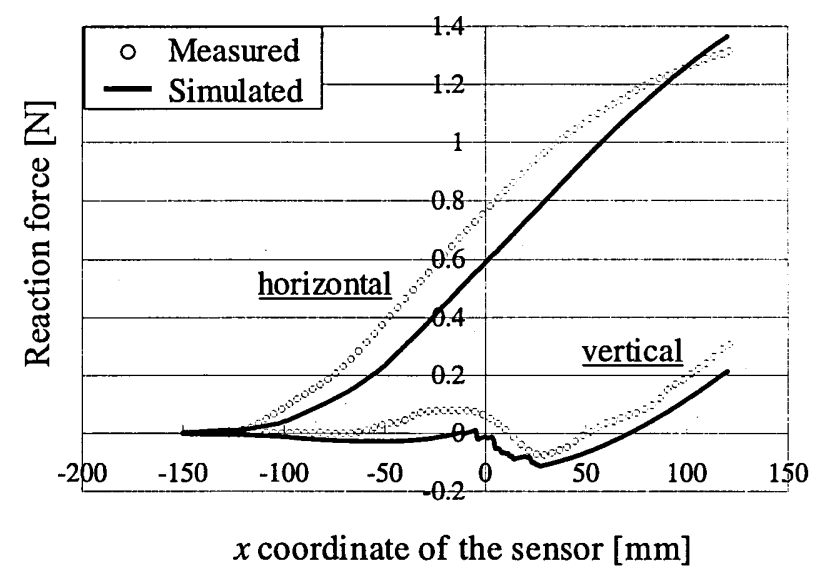

Fig. 8. Comparison between numerical analysis and measurement results of reaction forces (No. 1)

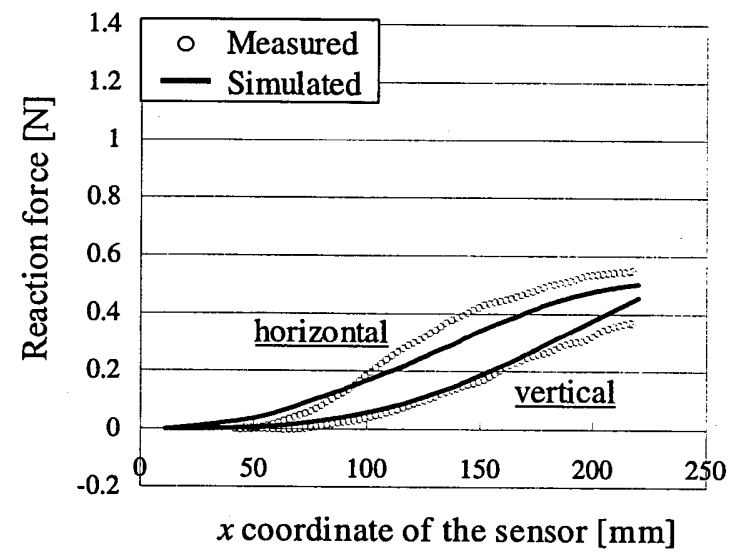

Fig. 9. Comparison between numerical analysis and measurement results of reaction forces (No. 2) 
comparison with measurements, but the results showed a generally high predictive accuracy. From above the results of this comparison, it was demonstrated that the reaction forces involving the effects of the initial shape were predicted specifically in the case of a bunch of rice stalks as well.

\section{CONCLUSIONS}

In the present study, previous analytical methods for the reaction force, taking into account the initial shape, were applied to a bunch of rice stalks, and the accuracy was assessed by experiment. The following conclusions were drawn from this study

1) The initial shape of a bunch of rice stalks was simulated based on the assessment parameters of shape. It was confirmed by comparison with actual images that the features of the bunch were simulated sufficiently. From this result, it was shown that the effect of the initial shape of the bunch could be considered for analysis of reaction forces.

2) The reaction forces of a bunch of rice stalks were analyzed according to their simulated initial shape. Reaction forces in both the horizontal and vertical directions were accurately predicted without depending on the initial shape. Thus, it was demonstrated that the reaction forces involving the effects of the initial shape were predicted specifically in the case of a bunch of rice stalks.

\section{ACKNOWLEDGEMENT}

The authors would like to thank Mr. Tashiro of our technical staff for his helpful support of our experiment. This research was supported by a grant from the Scientific Research Fund of the Ministry of Education, Culture, Sports, Science and Technology of Japan.

\section{REFERENCES}

Hirai, Y., E. Inoue, K. Hashiguchi, Y. K. Kim, S. Inaba and K. Tashiro 2000 Examination of calculation method for flexural rigidity of crop stalks. Proceedings of the Third International Conference on Agricultural Machinery Engineering (Korean Society for Agricultural Machinery), Vol. 2: 287-294

Hirai Y., E. Inoue, K. Mori and K. Hashiguchi 2002a Investigation of mechanical interaction between a combine harvester reel and crop stalks. Biosystems Engineering, 83(3): 307-317

Hirai Y., E. Inoue, K. Mori and K. Hashiguchi 2002b Analysis of reaction forces and posture of a bunch of crop stalks during reel operations of a combine harvester. the CIGR Jourmal of Scientific Research and Development (E-journal), Vol. IV

Hirai Y., E. Inoue, M. Matsui, K. Mori and K. Hashiguchi 2003a Reaction force of a wheat Stalk undergoing forced displacement. Journal of the Japanese Society of Agricultural Machinery, 65(2): $47-55$

Hirai Y., E. Inoue, M. Matsui, K. Mori and K. Hashiguchi 2003b Reaction force and posture of a bunch of wheat stalks undergoing forced displacement. Journal of the Japanese Society of Agricultural Machinery, 65(2): 56-63

Hirai Y., E. Inoue and K. Mori 2003c Numerical analysis of the reaction force of a single rice stalk undergoing forced displacement. Biosystems Engineering, 86(2): 179-189

Moustafa S. M. A., B. A. Stout and W. A. Bradley 1968 Elastic and inelastic stability of a biological structure. Journal of Agricultural Engineering Research, 13(1): 64-82

Muller Z. 1988 An investigation on mechanical and geometrical properties influencing the stability of 
wheat-stalk. In "Physical Properties of Agricultural Material and Products", Reznicek R. ed. Hemisphere Publishing Corporation, Washington, pp. 199-204

O'Dogherty M. J., J. A. Huber and C. J. Marshall 1995 A study of the physical and mechanical properties of wheat straw. Journal of Agricultural Engineering Research, 62: 133-142

Szot B. and G. Skubisz 1984 Characteristics of winter wheat stalk elasticity on the basis of measurements in field conditions. Zeszyty Problemowe Postepow Nauk Rolniczych, Warszawa, z. 243: $175-186$

Timoshenko S. 1958 Strength of Materials Part1, Elementary Theory and Problems. Van Nostrand, London, pp. 137-139 